\title{
Clinical presentation and management of primary ovarian neuroendocrine tumor in multiple endocrine neoplasia type 1
}

\author{
Sakshi Jhawar1,*, Rahul Lakhotia2,*, Mari Suzuki³, James Welch³, Sunita K Agarwal3, John Sharretts³, Maria Merino4, \\ Mark Ahlman5, Jenny E Blau³, William F Simonds³ and Jaydira Del Rivero6
}

'Eunice Kennedy Shriver National Institute of Child Health and Human Development, National Institutes of Health, Bethesda, Maryland, USA, 2Medical Oncology Service, Center for Cancer Research, National Cancer Institute, Clinical Center, National Institutes of Health, Bethesda, Maryland, USA, ${ }^{3}$ Metabolic Diseases Branch, National Institute of Diabetes and Digestive and Kidney Diseases, NIH, Bethesda, Maryland, USA, 4Laboratory of Pathology, National Cancer Institute, Clinical Center, National Institutes of Health, Bethesda, Maryland, USA, 5Radiology and Imaging Sciences, Clinical Center, National Institutes of Health, Bethesda, Maryland, USA, and 6Pediatric Oncology Branch, Center for Cancer Research, National Cancer Institute, Clinical Center, National Institutes of Health, Bethesda, Maryland, USA

*(S Jhawar and R Lakhotia contributed equally to this work)

Correspondence should be addressed to J Del Rivero Email

jaydira.delrivero@nih.gov

\section{Summary}

Multiple endocrine neoplasia type 1 (MEN1) is an autosomal dominant condition characterized by parathyroid, anterior pituitary and enteropancreatic endocrine cell tumors. Neuroendocrine tumors occur in approximately in 5-15\% of MEN1 patients. Very few cases of ovarian NETs have been reported in association with clinical MEN1 and without genetic testing confirmation. Thirty-three-year-old woman with MEN1 was found to have right adnexal mass on computed tomography (CT). Attempt at laparoscopic removal was unsuccessful, and mass was removed via a minilaparotomy in piecemeal fashion. Pathology showed ovarian NET arising from a teratoma. Four years later, patient presented with recurrence involving the pelvis and anterior abdominal wall. She was treated with debulking surgery and somatostatin analogs (SSAs). Targeted DNA sequencing analysis on the primary adnexal mass as well as the recurrent abdominal wall tumor confirmed loss of heterozygosity (LOH) at the MEN1 gene locus. This case represents to our knowledge, the first genetically confirmed case of ovarian NET arising by a MEN1 mechanism in a patient with MEN1. Extreme caution should be exercised during surgery as failure to remove an ovarian NET en masse can result in peritoneal seeding and recurrence. For patients with advanced ovarian NETs, systemic therapy options include SSAs, peptide receptor radioligand therapy (PRRT) and novel agents targeting mammalian target of rapamycin (mTOR) and vascular endothelial growth factor (VEGF).

\section{Learning points:}

- Ovarian NET can arise from a MEN1 mechanism, and any adnexal mass in a MEN1 patient can be considered as a possible malignant NET.

- Given the rarity of this disease, limited data are available on prognostication and treatment. Management strategies are extrapolated from evidence available in NETs from primaries of other origins.

- Care should be exercised to remove ovarian NETs en bloc as failure to do so may result in peritoneal seeding and recurrence.

- Treatment options for advanced disease include debulking surgery, SSAs, TKIs, mTOR inhibitors, PRRT and chemotherapy. 


\section{Background}

Multiple endocrine neoplasia type 1 (MEN1) is an autosomal dominant condition, caused by a germline mutation in the MEN1 gene, leading to the development of tumors of the parathyroid glands, anterior pituitary and enteropancreatic endocrine cells. NETs are welldifferentiated neuroendocrine neoplasms originating from enterochromaffin cells typically disseminated throughout the gastrointestinal and bronchopulmonary system and can also occur in patients with MEN1 (1). NETs are traditionally classified based upon the embryologic site of origin (foregut, midgut or hindgut), morphologic pattern and silver stain affinity differences (insular, trabecular, mucinous, strumal or mixed). Newer classification systems have been developed to emphasize the considerable clinical and histopathologic variability of NETs found within each embryologic site of origin. The most recent WHO 2017 classification differentiates pancreatic NETs into three grades (low, intermediate and high), and other gastrointestinal NETs into two grades (low and intermediate) on the basis of mitotic count per high power field and proliferative index (Ki-67) (2).

The majority of MEN1 syndrome-associated NETs are of foregut origin (thymus $24 \%$, bronchus $27 \%$, stomach $3 \%$ and duodenum 14\%). Ovarian NETs are rare, comprising $0.1 \%$ of all ovarian neoplasms, and very few cases of primary ovarian NET in patients with MEN1 syndrome have been reported in the literature $(1,3)$. However, none of the cases reported confirmed the origin of tumor by a MEN1 mechanism (loss of heterozygosity at MEN1 locus) $(1,4)$. Given their rarity, data regarding treatment of ovarian NETs are limited. Here, we present a case of primary ovarian NET arising from a teratoma in a patient with MEN1 with targeted DNA sequencing of the tumor. A brief discussion about challenges and recent advances in the management of primary ovarian NETs follows.

\section{Case presentation}

A 33-year-old female from Honduras previously diagnosed with a $1.1 \mathrm{~cm}$ macroprolactinoma treated with bromocriptine and primary hyperparathyroidism treated with a single gland parathyroidectomy was referred to the National Institutes of Health with a presumptive diagnosis of MEN1 syndrome for further workup.

\section{Investigation}

Targeted DNA sequencing demonstrated a heterozygous germline mutation in the MEN1 gene, c.219_220delCG (frameshift leading to premature protein truncation). The patient reported no family history consistent with MEN1.

On further evaluation, esophagogastroduodenoscopy showed two submucosal nodules in the second segment of the duodenum with confirmed histology of gastrinomas. Computed tomography (CT) imaging demonstrated $8.7 \times 7.7 \mathrm{~cm}$ right adnexal mass containing foci of soft tissue density and calcification. In-111 pentetreotide imaging (Octreoscan) demonstrated intense uptake associated with the lesion.

\section{Treatment}

Subsequent laparoscopic resection of the entire mass was attempted, but the mass was too large to be delivered en bloc. Operative approach was changed to a minilaparotomy and the mass was delivered in a piecemeal fashion. Pathology demonstrated a benign dermoid cyst with neuroendocrine tumor consistent with NET extending into peri-ovarian tissues. Tumor cells stained positive for synaptophysin, chromogranin, CD56 and TTF1, but were negative for neuron-specific enolase, calcitonin, serotonin and gastrin (Fig. 1).

\section{Outcome and follow-up}

After 4 years, she presented with a lower abdominal palpable mass. CT abdomen/pelvis showed an irregularly shaped, avidly enhancing multi-nodular $11.7 \times 8.7 \mathrm{~cm}$ mass arising from the pelvis; which extended through the anterior abdominal wall into the subcutaneous fat with additional satellite lesions within the anterior subcutaneous abdomen. The CT abnormalities corresponded to abnormally elevated Octreotide (In-111 pentetreotide) uptake. Biopsy of one of the subcutaneous lesions showed metastatic neuroendocrine neoplasm with Ki67 proliferation index of $2 \%$, consistent with patient's prior NET diagnosis (Fig. 1).

Targeted DNA sequencing analysis was performed for the patient's MEN1 mutation c.219-220delCG using DNA samples isolated from the two tumor specimens (a fragment of the right adnexal mass from 2009 and abdominal wall tumor from 2017). Predominantly mutant sequence was observed in both tumor specimens confirming LOH at the MEN1 gene locus (Fig. 2B).

After being lost to follow-up for 5 months, the patient presented with obstructive uropathy from nodal metastases and subsequent pyelonephritis. She underwent debulking surgery via exploratory laparotomy, panniculectomy, resection of metastatic abdominal wall tumors and 


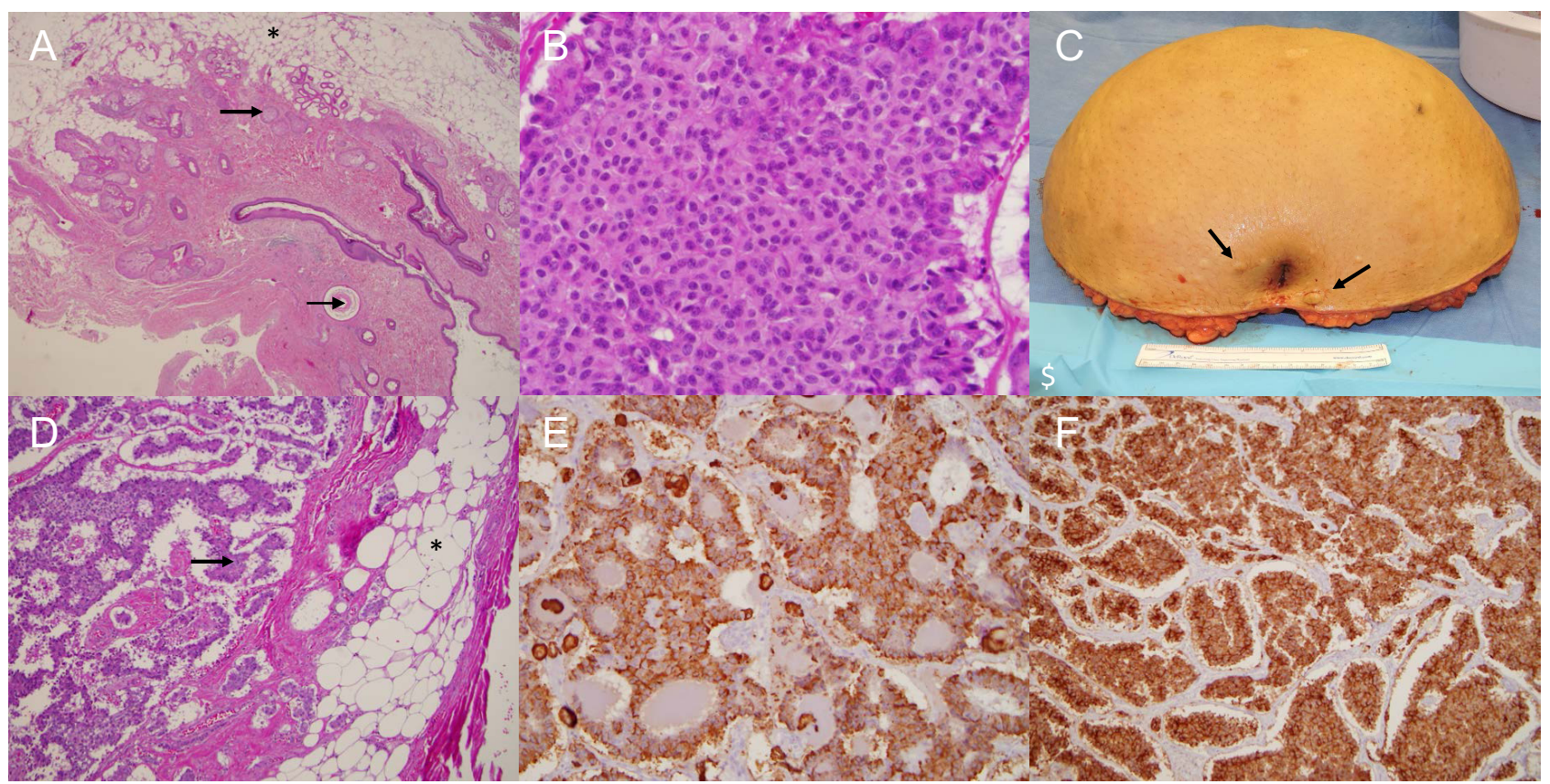

\section{Figure 1}

(A) Dermoid cyst from patient's first surgery with elements of hair follicles (arrowhead). Fat cells (star) and blood vessels (thin arrow). (B) 250x magnification showing tumor cells that are uniform, with a moderate amount of eosinophilic cytoplasm and finely granular nuclear chromatin. No necrosis or mitoses are seen. (C) Surgical specimen from removal of recurrent disease showing subcutaneous nodules. (D) Microscopy of recurrent tumor showing nests of tumor cells (arrow) involving the omental fat (star). The tumor cells stain positive for (E) chromogranin and (F) synaptophysin.

abdominal wall reconstruction. Post operatively, a CT abdomen was negative for residual disease and FDG-PET (fluorodeoxyglucose positron emission tomography) scan showed few scattered disease foci (Fig. 2A). She was commenced on monthly intramuscular long-acting octreotide $30 \mathrm{mg}$ injections. Six-month follow-up CT and FDG-PET showed stable disease.

\section{Discussion}

Primary ovarian NETs are rare neoplasms with an average age at diagnosis of 50.8 years (range 16-83 years) (5). Although most patients have some signs or symptoms at diagnosis, approximately 30\% patients are diagnosed incidentally. The most common presenting signs and symptoms are a palpable abdominal tumor, followed by abdominal pain, flushing, diarrhea and weight loss. In a published study of 329 patients with ovarian NETs, $57.4 \%$ of cases were associated with teratoma. However, association of ovarian NETs arising from a teratoma in a MEN1 patient is exceedingly rare. Spaulding et al. described one such case of synchronous association of ependymoma and NET with a mature cystic teratoma in a patient with MEN1 (3). However, genetic testing confirming the LOH at MEN1 locus was not performed. To our knowledge, this is the first reported case in the literature that shows the primary ovarian NETs can arise from a MEN1 mechanism in a dermoid cyst.

Since MEN1 can be associated with NETs of other origins - thymic, bronchial, gastric, duodenal and so forth, diagnosis of primary ovarian NET can be challenging. Once ovarian involvement with NET is identified, every attempt should be made to identify a secondary origin of the tumor. It is especially important to rule out a pancreatic primary as the treatment approaches and outcomes are different for pancreatic NETs versus NETs of other origin. Initial evaluation should include clinical manifestations, laboratory studies, imaging studies and in suspected cases of gastrointestinal origin of the NET - esophagogastroduodenoscopy and colonoscopy. Extrapolation of diagnostic imaging can be derived from sporadic gastroenteropancreatic neuroendocrine tumors (GEP-NETs). Potential primary sites of origin can be investigated using computed tomography (CT), magnetic resonance imaging (MRI) and somatostatin receptorbased diagnostic imaging (In-111 pentetreotide imaging or OctreoScan or ${ }^{68} \mathrm{Ga}$-DOTATATE positron emission tomography (PET) imaging). Furthermore, at initial diagnosis of advanced stage NETs, information from one of the somatostatin receptor-based imaging techniques can be predictive of clinical response to somatostatin receptor analog therapy (6). ${ }^{68} \mathrm{Ga}$-DOTATATE PET/CT is superior 


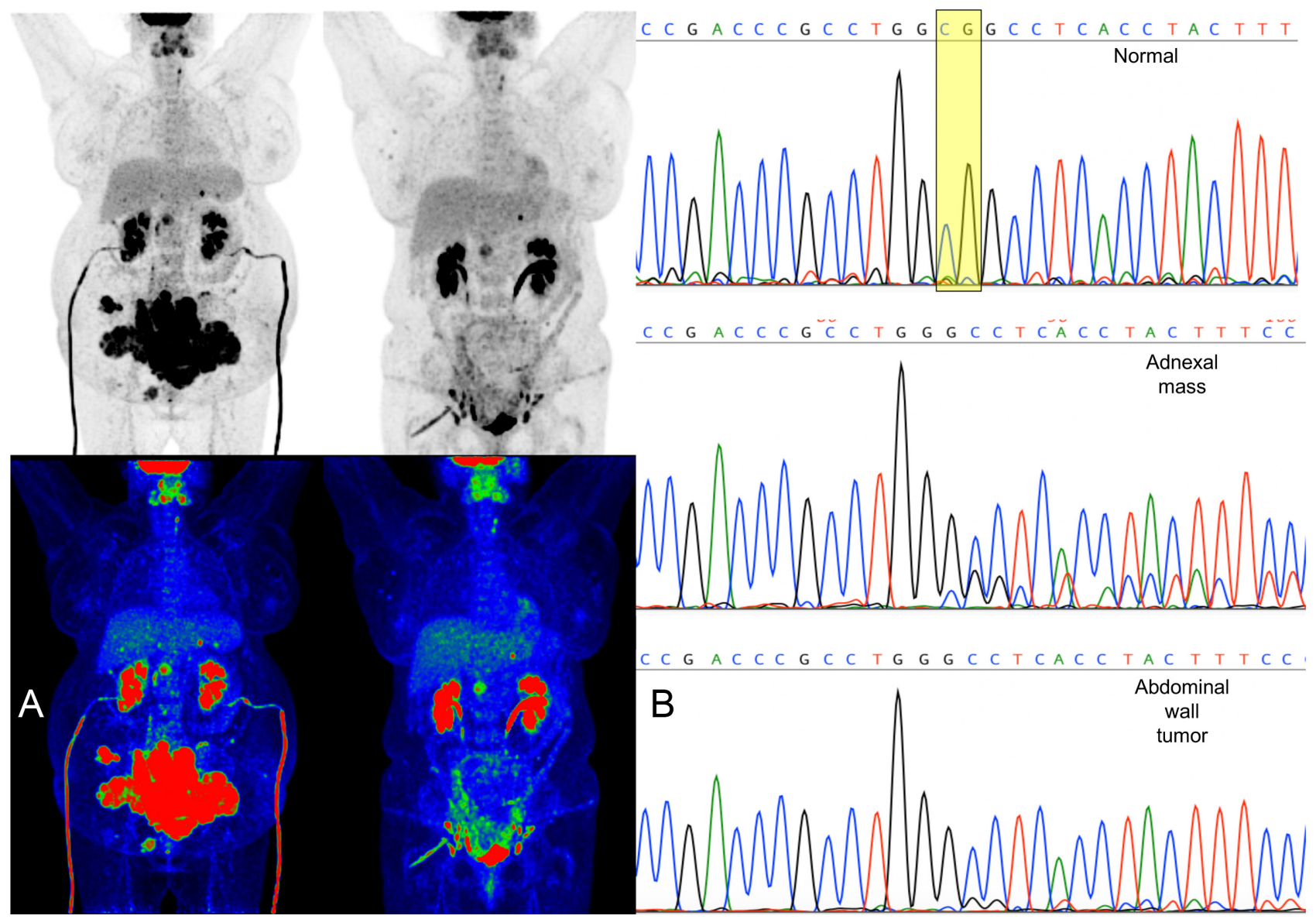

Figure 2

(A) FDG-PET images for our patient before surgery (left) and after surgery (right) demonstrating significant debulking of the dominant tumor mass and satellite lesions. (B) DNA sequence of MEN1 Exon-2 in the region affected by mutation c.219-220delCG. The two nucleotides (CG) deleted due to the mutation are highlighted in yellow in the normal sequence. DNA from the tumor specimens show predominantly mutant sequence compared to normal demonstrating $\mathrm{LOH}$ at the MEN1 locus.

to OctreoScan in detecting number of neuroendocrine lesions and may help guide treatment options (6).

Most ovarian NETs are confined to the ovary and are usually curable with surgery alone. If the diagnosis of NETs is known or suspected prior to the surgery, octreotide (100-500 $\mu \mathrm{g} \mathrm{SQ} / \mathrm{IV}$ every 6-12 h) should be administered immediately prior to and during the resection to prevent carcinoid crisis. National Comprehensive Cancer Network (NCCN) guidelines for neuroendocrine tumors recommends that the tumor be completely resected with the goal of attaining negative margins. Fertility-sparing surgery should be considered in women who may be interested in future pregnancy. In postmenopausal women, a more radical approach including hysterectomy and bilateral salpingo-oophorectomy may be considered (7). Cyst wall invasion, intraoperative rupture of the ovarian mass, tumor dissemination and adhesions are considered unfavorable prognostic factors and consideration should be given to a more radical surgical approach. This case also demonstrates the importance of removing the tumor en masse as failure to do so can result in peritoneal seeding and recurrence. Selected patients with limited metastases should undergo complete resection of the primary tumor and metastases with curative intent. Per NCCN guidelines, unresectable liver metastases should be considered for liver-directed therapies such as cryotherapy, radiofrequency ablation or regional embolization. In a case report, chemoembolization with cisplatin was effective in significant reducing the size of liver metastases from a primary ovarian NET (8). Skeletal metastases can be managed with radiation treatment. There is no current evidence to support adjuvant treatment (7).

Given the rarity of this disease, limited data are available on prognosis and management of primary ovarian NETs. Data from gastroenteropancreatic neuroendocrine tumors show that patients with localized 
NETs have $90.9 \%$ 5-year overall survival compared to $28.3 \%$ for metastatic disease. Long-term follow-up is important as relapses can occur at any time. This was demonstrated in a study of midgut NETs following an R0/ R1 resection where recurrences were seen up to 12 years after surgery, and also evidenced by our patient who recurred 4 years after initial surgery (9). Both CT and MRI can be used for initial diagnosis and follow-up; however, MRI is considered superior for detection and follow-up of liver metastases (10). However, the value of somatostatin receptor-based imaging for follow-up is not clear and is generally not recommended. Biomarkers such as plasma chromogranin A, serotonin and its metabolite urinary 5-hydroxyindoleacetic acid (5-HIAA) may be elevated and may sometimes be helpful to monitoring response to treatment or detecting relapses.

For unresectable or metastatic disease, treatment strategies are based on evidence and recommendations for GEP-NETs. Most asymptomatic patients with low tumor burden can be observed safely with imaging and biochemical markers such as serum serotonin, 5-HIAA (5-hydroxyindoleacetic acid) and chromogranin A. Caution should be exercised while interpreting biomarker results in patients with MEN1 syndrome as they can have other tumors resulting in elevation of these biomarkers (other neuroendocrine tumors, islet cell tumors and so forth). Patients with high tumor burden as presented here, or patients with symptoms due to tumor involvement or carcinoid syndrome, can undergo debulking surgery (7). If debulking surgery is warranted, cholecystectomy should also be performed if somatostatin receptor analog treatment is expected in future, given the associated risk of gallstones (11). Options for systemic therapy include somatostatin receptor analogs (SSAs), vascular endothelial growth factor (VEGF) or mammalian target of rapamycin (mTOR)-targeted agents, peptide receptor radioligand therapy (PRRT) and chemotherapy.

SSAs can be used for systemic treatment of advanced disease in patients with somatostatin receptor positivity on In-111 pentetreotide or ${ }^{68} \mathrm{Ga}$-DOTATATE PET/CT imaging. In a randomized trial including 85 patients with GEP-NETs; long-acting, repeatable (LAR) octreotide improved the progression-free survival (PFS) compared to placebo (median 14.3 vs 6 months, $P=0.000072$ ) (12). Another randomized trial comparing lanreotide with placebo in 88 patients demonstrated that lanreotide was associated with significantly higher rates of PFS at 24 months - 65.1\% (95\% CI, 54.0-74.1) compared to $33.0 \%$ (95\% CI, 23.0-43.3) in the placebo group $(P<0.001)(13)$. In addition to control of tumor growth, SSAs have been shown to highly effective in controlling symptoms of hormone oversecretion in over half of patients (14). Our patient is currently receiving LAR octreotide as an adjunct after surgery for the residual disease.

Peptide receptor radioligand therapy (PRRT) targeting the somatostatin receptor is another promising option. In a phase 3 trial comparing ${ }^{177} \mathrm{Lu}$ DOTATATE plus octreotide with octreotide alone, ${ }^{177} \mathrm{Lu}$ DOTATATE produced $18 \%$ responses compared to $3 \%$ in the control group $(P<0.001)$. PFS at month 20 was $65.2 \%(95 \% \mathrm{CI}$, 50.0-76.8) in the ${ }^{177} \mathrm{Lu}$ DOTATATE group and $10.8 \%$ (95\% CI, 3.5-23.0) in the control group $(P<0.001)$ (15). Therapies targeting VEGF (sunitinib, pazopanib, cabozantinib and axitinib) and mTOR (everolimus) have been used with promising results in NETs originating from other sites of the body (primarily gastrointestinal NETs and pancreatic NETs). Sunitinib was FDA approved for advanced pancreatic NETs after a phase III study showed PFS advantage compared to placebo (14). A summary of clinical studies with targeted agents in the treatment of advanced NETs is provided in Table 1. In a recently published case report, treatment with everolimus, an mTOR inhibitor, of a patient with right ovarian intermediate grade NET with liver metastases resulted in stable disease for more than 7 months, after the patient previously progressed on bleomycin, etoposide and cisplatin chemotherapy (16).

For ovarian NET patients progressing on novel therapies, chemotherapy can be used as a salvage option. Multiple agents including streptozocin, doxorubicin, 5-fluorouracil (5-FU), dacarbazine, actinomycin-D, bleomycin, cisplatin, etoposide, temozolomide, capecitabine, carboplatin and paclitaxel have been utilized individually and in various combinations for advanced NETs with variable success (objective response rates: $0-70 \%)(7)$. In a recent case series of patients with primary ovarian NETs, five patients received treatment with chemotherapy (varying protocols including doxorubicin or capecitabine or capecitabine, etoposide, platinum and temozolomide or cisplatin, 5-fluorouracil, and streptozocin); however, individual outcome data for these patients were not reported (17). Given significant toxicity and modest benefit, chemotherapy is usually reserved for situations when the patient has already received or is not eligible for above mentioned targeted therapies and SSAs.

In conclusion, an ovarian tumor in MEN1 patient should be considered as a possible malignant NET as evidenced by our patient who had a primary ovarian 
Table 1 Studies of targeted agents for treatment of NETs.

\begin{tabular}{|c|c|c|c|c|c|c|c|c|}
\hline Agent/class & Study type & Patients & Tumor type & Arm & PR (\%) & SD $(\%)$ & median & Comments \\
\hline \multicolumn{9}{|l|}{$\overline{\text { Bevacizumab }}$} \\
\hline \multirow[t]{2}{*}{ Bevacizumab vs IFNa-2b (14) } & $\begin{array}{l}\text { Phase } 2, \\
\text { randomized }\end{array}$ & 44 & All NETs & Bevacizumab & 18 & 77 & $\begin{array}{l}18 \text { weeks } \\
\text { PFS: } 95 \%\end{array}$ & \\
\hline & & & & IFNa & & 68 & $68 \%$ & \\
\hline \multirow[t]{2}{*}{$\begin{array}{l}\text { Bevacizumab + octreotide vs } \\
\text { IFNa + octreotide (14) }\end{array}$} & $\begin{array}{l}\text { Phase } 3 \text {, } \\
\text { randomized }\end{array}$ & 427 & All NETs & Bevacizumab & 0 & & $16.6 \mathrm{mo}$ & $P=0.55$ \\
\hline & & & & IFNa & 0 & & $15.4 \mathrm{mo}$ & \\
\hline $\begin{array}{l}\text { Octreotide + capecitabine } \\
\text { +bevacizumab (14) }\end{array}$ & Phase 2 & 45 & All NETS & & 17.8 & & $14.9 \mathrm{mo}$ & $\mathrm{BR}=52.9, \mathrm{SR}=82.3 \%$ \\
\hline \multirow[t]{2}{*}{$\begin{array}{l}\text { Bevacizumab + } \\
\text { temozolomide (14) }\end{array}$} & Phase 2 & 34 & pNETs & & 33 & & $14.3 \mathrm{mo}$ & OS: $33.3 \mathrm{mo}$ \\
\hline & & & Other NETs & & 0 & & $7.3 \mathrm{mo}$ & OS: $18.8 \mathrm{mo}$ \\
\hline \multirow[t]{2}{*}{ Bevacizumab + FOLFOX (18) } & $\begin{array}{l}\text { Pooled analysis } \\
\text { from two } \\
\text { phase } 2 \text { trials }\end{array}$ & 70 & pNETs & & 50 & & $21 \mathrm{mo}$ & \\
\hline & & & Other NETs & & 14 & & $19.3 \mathrm{mo}$ & \\
\hline \multirow[t]{2}{*}{ Bevacizumab + sorafenib (19) } & Phase 2 & 44 & pNETs & & 10.0 & 80 & NR & \\
\hline & & & Other NETs & & 9.7 & 87.1 & $11.4 \mathrm{mo}$ & \\
\hline \multicolumn{9}{|l|}{ Sunitinib } \\
\hline \multirow[t]{2}{*}{ Sunitinib (19) } & Phase 2 & 109 & pNETs (66) & & 16.7 & 68 & $7.7 \mathrm{mo}$ & \\
\hline & & & Other NETs (41) & & 2.4 & 83 & $10.2 \mathrm{mo}$ & \\
\hline \multirow[t]{3}{*}{ Sunitinib (19) } & & & & & & & & $\begin{array}{l}\text { Updated survival data } \\
\text { showed OS benefit }\end{array}$ \\
\hline & $\begin{array}{l}\text { Phase } 3 \text {, } \\
\quad \text { randomized }\end{array}$ & 171 & & Sunitinib & 9.3 & & $11.4 \mathrm{mo}$ & \\
\hline & & & & Placebo & 0 & & $5.5 \mathrm{mo}$ & \\
\hline \multicolumn{9}{|l|}{ Pazopanib } \\
\hline Pazopanib (14) & Phase 2 & 44 & Advanced NETs & & 9.1 & 47.7 & $9.5 \mathrm{mo}$ & \\
\hline \multirow[t]{2}{*}{ Pazopanib + octreotide (14) } & Phase 2 & 52 & pNETs (32) & & 21.9 & & $14.4 \mathrm{mo}$ & \\
\hline & & & Other NETs (20) & & 0 & & $8.4 \mathrm{mo}$ & \\
\hline \multirow[t]{3}{*}{ Cabozantinib (20) } & & & & & & & & $\begin{array}{l}81 \% \text { of all patients } \\
\text { required dose } \\
\text { reduction }\end{array}$ \\
\hline & Phase 2 & 61 & pNETs (20) & & 15 & 75 & $21.8 \mathrm{mo}$ & \\
\hline & & & Other NETs (41) & & 15 & 63.4 & $31.4 \mathrm{mo}$ & \\
\hline \multirow[t]{2}{*}{ Axitinib (14) } & & & & & & & & $\begin{array}{l}\text { Grade } 3 / 4 \\
\text { hypertension in } \\
63 \% \text { patients }\end{array}$ \\
\hline & Phase 2 & 30 & All NETs & & 3.0 & 70 & $26.7 \mathrm{mo}$ & \\
\hline \multicolumn{9}{|l|}{ Everolimus } \\
\hline \multirow[t]{2}{*}{ Everolimus \pm octreotide (19) } & Phase 2 & 160 & pNETs & Everolimus & 9.6 & 67.8 & $9.7 \mathrm{mo}$ & OS: $24.9 \mathrm{mo}$ \\
\hline & & & & Everolimus + octreotide & 4.4 & 80 & $16.7 \mathrm{mo}$ & OS: NR \\
\hline \multirow[t]{2}{*}{ Octreotide \pm everolimus (19) } & Phase 3 & 429 & All NETs & Octreotide & 2.0 & 81 & $11.3 \mathrm{mo}$ & \\
\hline & & & & Everolimus + octreotide & 2.4 & 84 & $16.4 \mathrm{mo}$ & \\
\hline \multirow[t]{3}{*}{ Everolimus (19) } & & & & & & & & $P>0.05$ \\
\hline & Phase 3 & 410 & pNETs & Everolimus & 5.0 & & $11.0 \mathrm{mo}$ & OS: 44 mo \\
\hline & & & & Supportive care & 2.0 & & $4.6 \mathrm{mo}$ & OS: $37.7 \mathrm{mo}$ \\
\hline \multirow[t]{3}{*}{ Everolimus (19) } & & & & & & & & $\begin{array}{l}\text { HR for reduction in } \\
\text { risk of death: } 0.64 \\
\text { (95\% Cl: } 0 \cdot 40-1 \cdot 05 \text { ), } \\
\text { one-sided } P=0.037\end{array}$ \\
\hline & Phase 3 & 302 & GI NETS & Everolimus & 2.0 & 81 & $11.0 \mathrm{mo}$ & \\
\hline & & & & Placebo & 1.0 & 64 & $3.9 \mathrm{mo}$ & \\
\hline
\end{tabular}

$\mathrm{BR}$, biochemical response; mo, months; SR, symptomatic response.

NET that arose via a MEN1 mechanism (germline MEN1 mutation and LOH at the MEN1 gene locus). Ovarian NETs with associated teratomas have better prognosis. Early surgical intervention for localized disease while exercising care to prevent intraoperative tumor spillage can result in excellent outcomes. Various treatment modalities are available for advanced disease including surgery, SSAs, targeted agents, PRRT and chemotherapy. Treatment should be undertaken in consultation with specialized centers, and wherever possible, patients should be encouraged to participate in clinical trials.

Declaration of interest

The authors declare that there is no conflict of interest that could be perceived as prejudicing the impartiality of this case report.

\section{Funding}

This work was supported by the National Institute of Diabetes and Digestive and Kidney Diseases (NIDDK). 


\section{Patient consent}

Written consent has been obtained from the patient.

\section{Author contribution statement}

$\mathrm{S}$ Jhawar and $\mathrm{R}$ Lakhotia contributed equally to the conception, writing and editing of the manuscript. M Suzuki: Endocrine fellow took care of the patient in the hospital and the outpatient clinic. Source for the surgical specimen image. J Blau, J Sharretts and W F Simonds: Endocrine attendings and primary providers in the clinical and research caring for the patient. Also involved in editing and revising the manuscript. R Lakhotia and J Del Rivero: Oncology fellow and oncology attending, respectively who consulted on the patient when she presented with relapse. J Del Rivero: Performed final editing of the manuscript and responsible for the decision to submit for publication. J Welch and S Agarwal: Performed DNA sequencing on the tumor. M Ahlman: Radiologist involved in interpretation and selection of anatomic and nuclear imaging for publication. M Ahlman also edited the manuscript. M Merino: Pathologist involved in interpretation of tumor pathology and selection of microscopic images for publication.

\section{References}

1 Duh QY, Hybarger CP, Geist R, Gamsu G, Goodman PC, Gooding GA \& Clark OH. Carcinoids associated with multiple endocrine neoplasia syndromes. American Journal of Surgery 1987154 142-148. (https://doi.org/10.1016/0002-9610(87)90305-9)

2 Kloppel G, Perren A \& Heitz PU. The gastroenteropancreatic neuroendocrine cell system and its tumors: the WHO classification. Annals of the New York Academy of Sciences 20041014 13-27. (https:// doi.org/10.1196/annals.1294.002)

3 Spaulding R, Alatassi H, Stewart Metzinger D \& Moghadamfalahi M. Ependymoma and carcinoid tumor associated with ovarian mature cystic teratoma in a patient with multiple endocrine neoplasia I. Case Reports in Obstetrics and Gynecology 20142014 712657. (https:// doi.org/10.1155/2014/712657)

4 Modlin IM, Lye KD \& Kidd M. A 5-decade analysis of 13,715 carcinoid tumors. Cancer 200397 934-959. (https://doi.org/10.1002/ cncr.11105)

5 Soga J, Osaka M \& Yakuwa Y. Carcinoids of the ovary: an analysis of 329 reported cases. Journal of Experimental and Clinical Cancer Research 200019 271-280.

6 Janson ET, Westlin JE, Eriksson B, Ahlstrom H, Nilsson S \& Oberg K. [111In-DTPA-D-Phe1]octreotide scintigraphy in patients with carcinoid tumours: the predictive value for somatostatin analogue treatment. European Journal of Endocrinology 1994131 577-581.

7 Gardner GJ, Reidy-Lagunes D \& Gehrig PA. Neuroendocrine tumors of the gynecologic tract: a Society of Gynecologic Oncology (SGO) clinical document. Gynecologic Oncology 2011122 190-198. (https:// doi.org/10.1016/j.ygyno.2011.04.011)

8 Kanayama S, Yamada Y, Tanase Y, Haruta S, Nagai A, Kawaguchi R, Yoshida S, Furukawa N, Oi H \& Kobayashi H. A case of early-stage ovarian carcinoid tumor metastasized to the liver. Case Reports in Obstetrics and Gynecology 20122012 961087. (https://doi. org/10.1155/2012/961087)

9 Cives M, Anaya DA, Soares H, Coppola D \& Strosberg J. Analysis of postoperative recurrence in stage I-III midgut neuroendocrine tumors. Journal of the National Cancer Institute 2018110 282-289. (https://doi.org/10.1093/jnci/djx174)
10 Sundin A, Vullierme MP, Kaltsas G, Plockinger U, Mallorca Consensus Conference Participants \& European Neuroendocrine Tumor Society. ENETS Consensus Guidelines for the standards of care in neuroendocrine tumors: radiological examinations. Neuroendocrinology 200990 167-183. (https://doi. org/10.1159/000184855)

11 Oberg K, Kvols L, Caplin M, Delle Fave G, de Herder W, Rindi G, Ruszniewski P, Woltering EA \& Wiedenmann B. Consensus report on the use of somatostatin analogs for the management of neuroendocrine tumors of the gastroenteropancreatic system. Annals of Oncology 200415 966-973. (https://doi.org/10.1093/annonc/ mdh216)

12 Rinke A, Muller HH, Schade-Brittinger C, Klose KJ, Barth P, Wied M, Mayer C, Aminossadati B, Pape UF, Blaker M, et al. Placebocontrolled, double-blind, prospective, randomized study on the effect of octreotide LAR in the control of tumor growth in patients with metastatic neuroendocrine midgut tumors: a report from the PROMID Study Group. Journal of Clinical Oncology 200927 4656-4663. (https://doi.org/10.1200/JCO.2009.22.8510)

13 Caplin ME, Pavel M, Cwikla JB, Phan AT, Raderer M, Sedlackova E, Cadiot G, Wolin EM, Capdevila J, Wall L, et al. Lanreotide in metastatic enteropancreatic neuroendocrine tumors. New England Journal of Medicine 2014371 224-233. (https://doi.org/10.1056/ NEJMoa1316158)

14 Crabtree JS. Clinical and preclinical advances in gastroenteropancreatic neuroendocrine tumor therapy. Frontiers in Endocrinology 20178 341. (https://doi.org/10.3389/fendo.2017.00341)

15 Brabander T, van der Zwan WA, Teunissen JJM, Kam BLR, Feelders RA, de Herder WW, van Eijck CHJ, Franssen GJH, Krenning EP \& Kwekkeboom DJ. Long-term efficacy, survival, and safety of $[(177) \mathrm{Lu}-\mathrm{DOTA}(0), \operatorname{Tyr}(3)]$ octreotate in patients with gastroenteropancreatic and bronchial neuroendocrine tumors. Clinical Cancer Research 201723 4617-4624. (https://doi. org/10.1158/1078-0432.CCR-16-2743)

16 Kaiho-Sakuma M, Toyoshima M, Watanabe M, Toki A, Kameda S, Minato T, Niikura H \& Yaegashi N. Aggressive neuroendocrine tumor of the ovary with multiple metastases treated with everolimus: a case report. Gynecologic Oncology Reports 201823 20-23. (https://doi. org/10.1016/j.gore.2018.01.002)

17 Preda VA, Chitoni M, Talbot D, Reed N \& Grossman AB Primary ovarian carcinoid: extensive clinical experience with an underrecognized uncommon entity. International Journal of Gynecological Cancer 201828 466-471. (https://doi.org/10.1097/ IGC.0000000000001215)

18 Kunz PL, Balise RR, Fehrenbacher L, Pan M, Venook AP, Fisher GA, Tempero MA, Ko AH, Korn WM, Hwang J, et al. Oxaliplatin-fluoropyrimidine chemotherapy plus bevacizumab in advanced neuroendocrine tumors: an analysis of 2 phase II trials. Pancreas 201645 1394-1400. (https://doi.org/10.1097/ MPA.0000000000000659)

19 Lee A, Chan DL, Wong MH, Li BT, Lumba S, Clarke SJ, Samra J \& Pavlakis N. Systematic review of the role of targeted therapy in metastatic neuroendocrine tumors. Neuroendocrinology 2017104 209-222. (https://doi.org/10.1159/000446115)

20 Chan JA, Faris JE, Murphy JE, Blaszkowsky LS, Kwak EL, McCleary NJ, Fuchs CS, Meyerhardt JA, Ng K, Zhu AX, et al. Phase II trial of cabozantinib in patients with carcinoid and pancreatic neuroendocrine tumors (pNET). Journal of Clinical Oncology 2017 35 (4 Supplement) 228. (https://doi.org/10.1200/JCO.2017.35.4 suppl.228)

Received in final form 4 June 2019

Accepted 30 July 2019 